\title{
An overall performance index for wind farms: a case study in Norway Arctic region
}

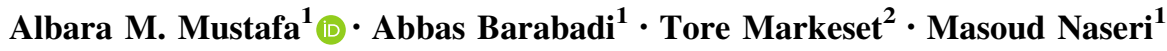

Received: 11 November 2020/Revised: 23 April 2021/Accepted: 31 May 2021/Published online: 12 June 2021

(C) The Author(s) 2021

\begin{abstract}
Wind farms (WFs) experience various challenges that affect their performance. Mostly, designers focus on the technical side of WFs performance, mainly increasing the power production of WFs, through improving their manufacturing and design quality, wind turbines capacity, their availability, reliability, maintainability, and supportability. On the other hand, WFs induce impacts on their surroundings, these impacts can be classified as environmental, social, and economic, and can be described as the sustainability performance of WFs. A comprehensive tool that combines both sides of performance, i.e. the technical and the sustainability performance, is useful to indicate the overall performance of WFs. An overall performance index (OPI) can help operators and stakeholders rate the performance of WFs, more comprehensively and locate the weaknesses in their performance. The performance model for WFs, proposed in this study, arranges a set of technical and sustainability performance indicators in a hierarchical structure. Due to lack of historical data in certain regions where WFs are located, such as the Arctic, expert judgement technique is used to determine the relative weight of each performance indicator. In addition, scoring criteria are predefined qualitatively for each
\end{abstract}

Albara M. Mustafa

Albara.m.mustafa@uit.no

Abbas Barabadi

abbas.b.abadi@uit.no

Tore Markeset

tore.markeset@uis.no

Masoud Naseri

masoud.naseri@uit.no

1 UiT The Arctic University of Norway, Troms $\varnothing$, Norway

2 University of Stavanger, Stavanger, Norway performance indicator. The weighted sum method makes use of the relative weights and the predefined scoring criteria to calculate the OPI of a specific WF. The application of the tool is illustrated by a case study of a WF located in the Norwegian Arctic. Moreover, the Arctic WF is compared to another WF located outside the Arctic to illustrate the effects of Arctic operating conditions on the OPI.

Keywords Wind farms - Overall performance index · Weighted sum method $\cdot$ Scoring criteria $\cdot$ Expert judgment

\section{Introduction}

Wind energy investments in the Arctic region is appealing because of the higher availability of wind power, which is almost $10 \%$ higher than in other regions due to the higher density of air Fortin et al. (2005). Moreover, the Arctic region is sparsely populated, which makes it even more attractive for wind energy investments. However, the performance of wind farms (WFs) located in the Arctic is faced with a plethora of challenges. Most of these challenges are attributed to operating in severe weather conditions such as low temperatures, ice accretion on the blades and snow accumulation on roads. These weatherrelated challenges affect mainly the technical performance of WFs. For example, ice accretion on WT blades creates mass imbalances and instantaneous losses in power production, which, under certain conditions, can reach $30 \%$ of the power produced, even in light icing events, Laakso and Peltola (2005), or in severe icing conditions, leading to total shutdown of the wind turbine (WT).

Technical performance is related to the technical functions of WFs, in terms of the amount of electricity generated Koo et al. (2018).It also refers to the quality of the 
power produced by the WF, as well as their capacity and availability performances. Availability performance can be described in terms of the reliability, maintainability and supportability of the wind farms, IEC (2015). Figure 1 illustrates the proposed technical performance indicators.

The quality performance indicator reflects the design and manufacturing quality of WTs and the WF layout Zaki (2020). The availability performance indicator depends, for the most part, on the reliability, maintainability and supportability of the wind farm IEC (2015) and Naseri and Barabady (2016), and the capacity performance indicator reflects the maximum power delivered by the wind farm, considering the operating conditions in the respective region (Barabady et al. 2010).

The primary objective of this work is to devise a method for calculating the Overall Performance of WFs and to evaluate the mutual impacts of WTs on their surroundings and impact of the surrounding environment on WTs.

The impacts of WTs on their surroundings can be summarized into three categories, namely: social and safety impacts, environmental impacts, and economic impacts. According to Musango and Brent (2011) and Kucukali (2016), these three types of impacts can be grouped under sustainability performance of WFs, as shown in Fig. 1. It is worth noting that many sustainability indicators can be included to describe the sustainability of WFs; however, these three indicators are described as the traditional pillars of sustainability Diaz-Balteiro et al. (2017).

The social and safety impacts constitute hazards such as noise generated by the WTs during construction and operation, traffic on public roads caused by transporting large WTs components, and ice fall and ice throw from WTs that can harm humans, animals and nearby structures, Mustafa et al. (2019). Other concerns related to the social and safety impacts are,for example, the visual pollution that might detract from pristine views or hinder tourism, and doubts related to that WFs might interfere with the operation of military radar systems Welch and Venkateswaran (2009). In addition, there are claims such as that governments are violating the rights of indigenous communities, by approving wind energy projects, causing cultural destruction. For example, constructing wind farms on Sámi lands in northern Scandinavia, may be considered unethical and overtly political, simply because it might come across as a systematic dispossession of their lands, and a lack of recognition of their rights Lawrence and Moritz (2019).

The environmental impacts of WTs can be positive such as the carbon-free electricity production, no long-term waste and no cooling water required, for these concerns, WFs are environmentally benign. On the other hand, chemical deicing used to remove ice from the blades of WTs, and birds and bats mortalities caused by WTs, are examples of the negative impacts of WFs. However, the number of birds killed by WTs may be negligible compared to that by fossil fuels, and some other human activities Sovacool (2009). In addition, water pollution in some areas, during the construction phase of WFs Lu et al. (2019), is another example of negative environmental impacts caused by WFs.

The economic impacts are described as being crucial for wind energy investment in any country, Kucukali (2016). Examples of these impacts are the job opportunities created by WFs projects for local communities, stabilizing the prices of electricity as the country will not be dependent on a single source to produce its electricity and help in lowering the prices of electricity. This, however, is dependent on the cost of electricity produced by the WF.

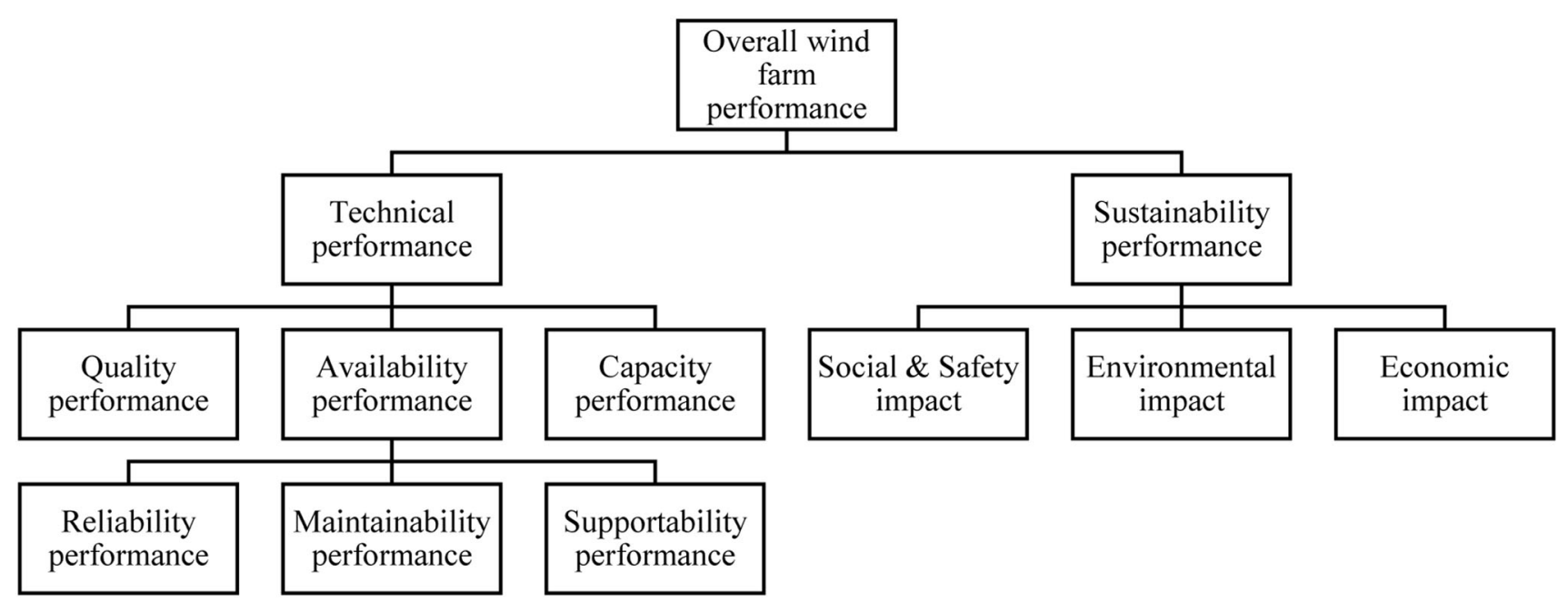

Fig. 1 The overall performance model for wind farms 
Most wind energy projects are subsidized by governments due to their high capital and operational costs. Without governments' subsidies, wind energy projects will yield negative returns, and investors will find it difficult to cover for the cost of involved risks Welch and Venkateswaran (2009). However, if the capital costs of wind energy investments were reduced and the utilization rate of WTs increased, which is the percentage of time a WT can be in use during the $8760 \mathrm{~h}(365 \times 24)$ of the year, the wind energy projects would have positive returns on investments, without even the subsidies from governments. Furthermore, as the cost of sources of energy such as oil and natural gas become more expensive, wind energy becomes more competitive. Therefore, the accelerated increase in technology development that we witness every day, and the rise in oil and gas prices, will put wind energy on a short path to become financially self-sustaining and will have positive economic impact on investors and societies.

The proposed model combines the technical and sustainability performances and can be applied to model the performance of WFs, located in cold climate regions such as the Arctic region, as well as other regions that are not characterized by cold climate conditions. In this paper, this model is used to evaluate the overall performance of a WF in Arctic Norway.

The majority of current studies on the performance of WFs in the Arctic focus on the effects of icing on WTs in terms of their structural behavior Alsabagh et al. (2013), resulting power losses Kilpatrick et al. (2020), anti/de-icing technologies Wei et al. (2020) Dai et al. (2012) Parent and Ilinca (2011) and risks caused by ice fall, ice throw and thrown blade parts Bredesen and Refsum (2015) Rastayesh et al. (2019). These studies mostly focus on the technical performance of WTs. It is observed that an integrated approach covering both the technical and sustainability performances of WFs is lacking.

The rest of this paper is organized as follows: in Sect. 2 the methodology adopted for calculating the OPI for WFs using the WSM, expert judgements, and the predefined scoring criteria is presented. Section 3 presents the application of the methodology on a WF located in Arctic Norway. The conclusions and findings of this work are presented in Sect. 4.

\section{Weighted sum method for OPI calculation}

There are several multiple-criteria decision-making methods that can be used in the decision-making process such as weighted sum method (WSM), weighted product method (WPM), analytical hierarchy process (AHP), technique for order of preference by similarity to ideal solution (TOPSIS), etc. The common characteristic of these methods is that the analysis of the alternatives is based on determined criteria Bögüurcü (2012). WSM, which is used in this paper, is one of the oldest and most-widely used methods in multi-criteria decision-making (MCDM) Triantaphyllou (2000). For example, Stanujkic and Zavadskas (2015) used WSM to introduce an approach that helps decision makers to choose the best alternative, considering both the highest unit performance and the preferred performance, Kucukali (2016) developed a risk score card to rank the wind energy projects in Turkey using WSM and expert judgement. In addition, Williamson et al. (2014) used the WSM method to select the most appropriate low-head hydro-turbine alternatives by using quantitative and qualitative scoring.

The basic idea of the WSM is to calculate the OPI as a sum of products of performance relative weights and scores of criteria, as follows in Eq. 1, Stanujkic and Zavadskas (2015):

$O P I=\sum_{i=1}^{n} w_{i} \times S_{i}$

where $w_{i}$ is the relative weight of the performance indicator $i, S_{i}$ is the criteria score for the performance indicator $i$. Figure 2 shows the steps followed in calculating the OPI for WFs using the WSM method. At first, the relative weight of each of the performance indicator shown in Fig. 1 needs to bdetermined. In case of lack of such data, the relative weight of performance categories is determined using expert judgment technique, explained in Sect. 2.1.

Secondly, a set of qualitative scoring criteria is to be developed to define the scores for each performance indicator. The scoring criteria reflect the different levels of performance a WF can operate according to. The scoring for each performance indicator can be divided into 4 levels, where level 1 reflects the minimum level of performance and level 4 is the highest. The scoring criteria is illustrated in Sect. 2.2.

Thirdly, the performance index for each performance indicator is calculated using Eq. (1), where the relative weight is obtained from experts and the performance score is obtained from the scoring criteria table (Table 2 in Sect. 2.2), which is based on the characteristics of the selected WF. The same process is repeated to calculate the performance index for each indicator up to the overall performance index of the WF.

Finally, we end up with a value of OPI that reflects how well or degraded the performance of a specific WF is. This index is instrumental for WFs operators and stakeholders to identify weaknesses in performance, in order to take the proper measures to alleviate them in cases, where the overall performance index was below the acceptable limit. 


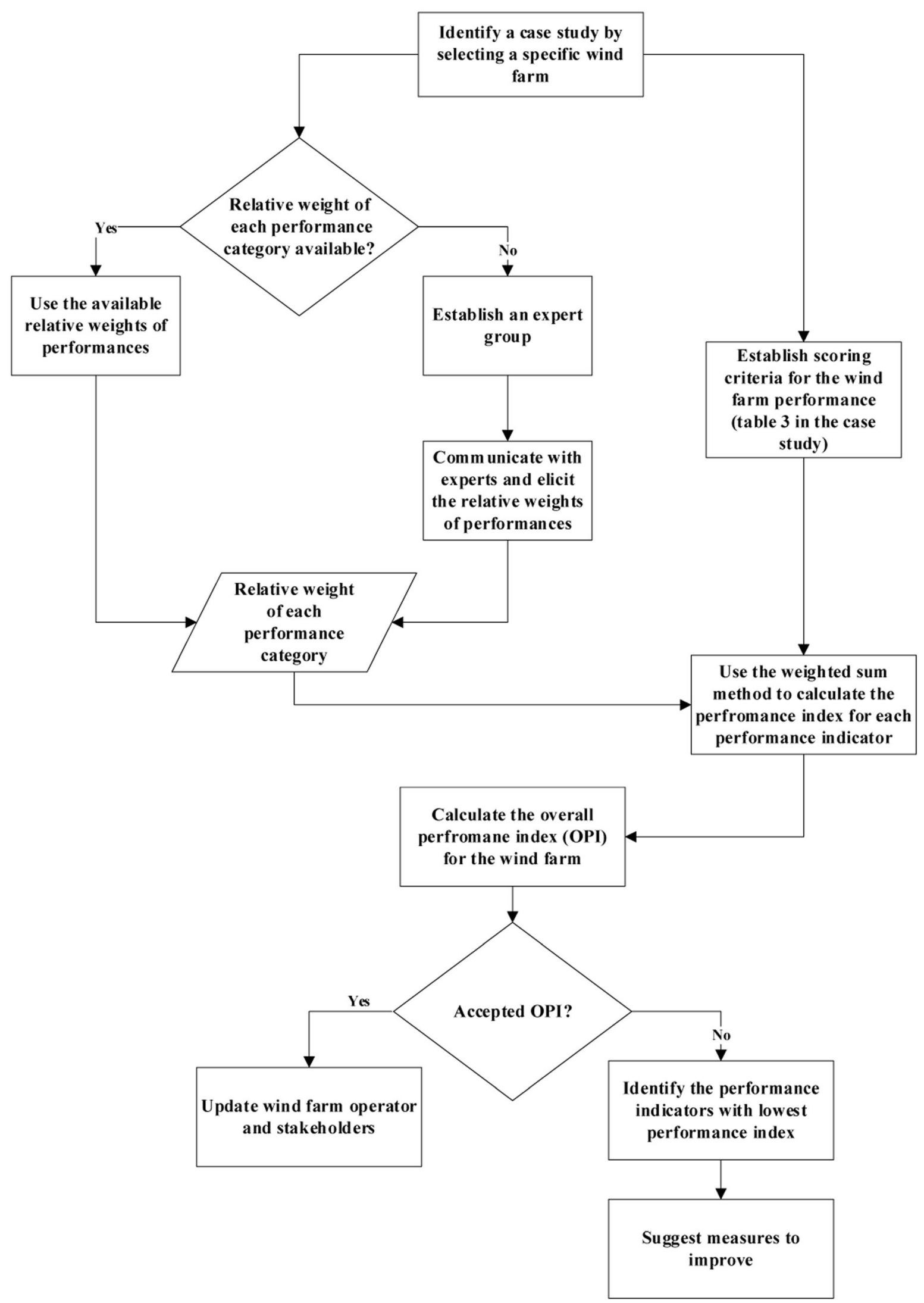

Fig. 2 Overall performance index calculation methodology 
A flow chart indicating the evaluation methodology of OPI is shown in Fig. 2. A case study will be presented to demonstrate the application of this methodology.

\subsection{Expert judgements}

Wind energy applications in Arctic Norway are relatively new. For example, in 2010, the total installed wind energy capacity in Norway was $436 \mathrm{MW}$, with only $48 \mathrm{MW}$ installed in the Arctic Battisti (2015). As such, long term data on the performance of WTs in Arctic Norway is far from satisfactory, which emphasizes the need for experts' knowledge that can contribute significantly to determining the relative weight of each performance indicator. However, expert judgement technique is indispensable even in situations where data is satisfactorily available as the statistical treatment of data cannot replace the expert judgments in the operational risk management process in hydropower plants, Mermet and Gehant (2011) as well as wind power plants.

Expert judgement is recognized as a type of scientific data and methods are developed for treating it as such. This technique is typically applied when there is substantial uncertainty regarding the true values of certain variables, Colson and Cooke (2018). It entails selecting experts with relevant experience (i.e. wind energy) and communicating with them, in order to elicit the needed information (i.e. the relative weight of each performance indicator). The Elicitation processes can involve simple correspondence, questionnaires, personal interviews (by telephone or in person) and various other combinations of interactions Beaudrie et al. (2016).

Each expert, in the elicitation process, can either be calibrated by giving his/ her answer a certain weight, that reflects the strength of the answer among other answers. The calibration process can consider, for example, the number of years of experience the expert has, the more experience the expert has the more important his answer is, compared to other experts' answers, example of that can be found in Naseri et al. (2015). In another approach, all experts can be treated as the same with having equal importance for their answers. For simplicity, the latter approach is the one used in this case study.

The selected group of experts in this study had expertise that ranged from academic doctors, and professors at universities involved in wind energy technologies to that of operators, engineers, and managers at WFs in Arctic Norway. Experts were interviewed physically or through distant conference meetings. Other means of communication with experts were telephone and email. Experts were asked to participate in a questionnaire that aimed to assess the relative weights of the performance indicators defined in the proposed model in Fig. 1. In total, 12 experts participated in answering the questionnaire. It is extremely unlikely that experts will ever be in total agreement with one another when answering questions where uncertainty is substantial.

The questionnaire consisted of 11 questions, covering all the 11 performance indicators. The meaning and aspects of each performance indicator were explained to the experts for each question to avoid ambiguity. Experts were asked to assess the relative weight of each performance indicator qualitatively, by ranking each one from 1 to 10 , where 1 indicated the lowest importance and 10 indicated the highest importance.

Afterwards, experts' rankings were summed for each performance indicator, as shown in Table 1. The average weight of each performance indicator $(P I)$ was calculated by dividing the sum of weight rankings from experts by the number of experts $(n)$, as presented in Eq. (2).

$P I$ average weight $=\frac{\sum_{n=1}^{n} \text { ranks of } P I}{n}$.

To calculate the relative weight of each performance indicator, the resulting average weight for each indicator is divided by the total weight for each group of performance indicators. For example, the availability performance represents a group of performance indicators that includes the reliability, maintainability, and supportability performance indicators. In order to calculate the relative weight of reliability performance, the average weight of reliability, which is 8.08 as per Table 2, is divided by the sum of the average weight of reliability $(R)$, maintainability $(M)$ and supportability $(S)$, which is equal to 23.54 . The relative weight of reliability in that case is equal to $34 \%$ as per Eq. 3 . The same applies to maintainability and supportability performance indicators, with the relative weight equal to $33 \%$ for each, and to the rest of other performan indicators.

$$
\begin{aligned}
\text { Reliability PI relative weight } & =\frac{\text { average weight of }(R)}{\sum \text { average weight }(R, M, S)} \\
& =\frac{8.08}{8.08+7.64+7.82} \\
& =0.34
\end{aligned}
$$

Figure 3 summarizes the relative weight of each performance indicator assessed by the experts. According to experts, there is a slight difference between the technical and sustainability performances in terms of their relative weights; this was indicated by assigning a higher relative weight $(54 \%)$ to technical performance. Through discussion, experts explained that by improving the technical performance will improve the sustainability performance aspects, i.e. the social, economic, and environmental aspects. Therefore, the technical performance was assigned a higher relative weight. 
Table 1 Relative weight of performance indicators assessed by experts (1: lowest importance, 10: highest importance)

\begin{tabular}{|c|c|c|c|c|c|c|c|c|c|c|c|}
\hline & & & & & & & & & & \multicolumn{2}{|c|}{ Overall performance } \\
\hline & & & & \multicolumn{3}{|c|}{ Technical performance } & \multicolumn{3}{|c|}{ Sustainability performance } & $\begin{array}{c}\text { Technical } \\
1-10\end{array}$ & $\begin{array}{c}\text { Sustainability } \\
1-10\end{array}$ \\
\hline & \multicolumn{3}{|c|}{ Availability Performance } & $\begin{array}{c}\text { Quality } \\
1-10\end{array}$ & $\begin{array}{c}\text { Availability } \\
1-10\end{array}$ & $\begin{array}{c}\text { Capacity } \\
1-10\end{array}$ & $\begin{array}{c}\text { Social } \\
1-10\end{array}$ & $\begin{array}{c}\text { Environmental } \\
1-10\end{array}$ & $\begin{array}{c}\text { Economic } \\
1-10\end{array}$ & & \\
\hline & $\begin{array}{c}\text { Reliability } \\
1-10\end{array}$ & $\begin{array}{c}\text { Maintainability } \\
1-10\end{array}$ & $\begin{array}{c}\text { Supportability } \\
1-10\end{array}$ & & & & & & & & \\
\hline Sum weight & 97 & 84 & 86 & 71 & 95 & 76 & 75 & 92 & 91 & 96 & 83 \\
\hline Average weight & 8.08 & 7.64 & 7.82 & 5.92 & 8.64 & 6.91 & 6.25 & 7.67 & 7.58 & 8.00 & 6.92 \\
\hline Relative weight & 0.34 & 0.33 & 0.33 & 0.28 & 0.40 & 0.32 & 0.29 & 0.36 & 0.35 & 0.54 & 0.46 \\
\hline
\end{tabular}

It can be seen from the Fig. 3 that all three performance indicators under the availability performance, i.e. the reliability, maintainability, and supportability, have almost the same relative weight. The experts have assigned the availability performance a higher relative weight $(40 \%)$ compared to capacity and quality performances, which had relative weights of $32 \%$ and $28 \%$, respectively as shown in Fig. 4. The experts have assessed that the environmental and economic performance indicators represent more than $70 \%$ of the total relative weight under sustainability performance, with the social performance indicator having $29 \%$ as a relative weight.

The next step, after determining the relative weights, is to define the scoring criteria for each performance indicator. The selected score from the predefined criteria is mainly dependent on the performance characteristics of the selected WF.

\subsection{Performance scoring criteria}

A set of criteria was defined for each performance indicator, with specific scores from 1 to 4 , as shown in Table 2, which is established based on a literature review, measured data, documented evidence, and human reasoning. Selecting criteria scores are dependent on the specifications and performance characteristics of the WF under study, which can include technical characteristics, location, and WF impact on its surroundings. An example of the use of scoring criteria was shown by the Japan International Cooperation Agency JICA JICA (2011), in which a scoring criteria was used to assess the environmental and societal impacts of infrastructure projects around the world.

As can be seen from Table 2, the scores for availability, technical and sustainability performance indicators are not defined. This is because these performance indicators are functions of the performance indicators under them. In order to obtain the scores of these undefine performance indicators, the WSM can be used. As an example, Eq. (4) shows the method for calculating the criteria score for availability performance, which is equal to the sum of products of the relative weights of Reliability $(R)$, Maintainability $(M)$ and Supportability $(S)$ indicators, and their criteria scores, taken from Table 2 for a specific WF.

Availability score $\left(S_{A}\right)=w_{R} \times S_{R}+w_{M} \times S_{M}+w_{S} \times S_{S}$.

where $w_{R}, w_{M}, w_{S}$ are the relative weights of reliability, maintainability, and supportability respectively, and $S_{R}$, $S_{M}$, and $S_{S}$ are their criteria scores. Similarly, the overall WF score of a WF can be calculated as a function of its technical and sustainability performance indicators using Eq. (5) below:

Overall WF performance score $=w_{\text {tech }} \times S_{\text {tech }}+w_{\text {sus }} \times S_{\text {sus }}$.

where $w_{\text {tech }}$ and $w_{\text {sus }}$ are the relative weights of the technical and sustainability performance indicators respectively, assessed by the experts. $S_{\text {tech }}$ and $S_{\text {sus }}$ are the criteria scores, calculated using equations similar to Eq. (4) for the technical and sustainability performances.

\section{Calculating OPI for Fakken wind farm: a case study}

The Arctic region considered in this case study is the northern $\mathrm{rt}$ of Norway, which experiences warmer temperatures than cities further south in the overall Arctic region, such as Canada or the United States. The coastal part of Arctic Norway is recognized to be ice free. Therefore, some WFs installed close to the coast do not need to equip their WTs with anti-icing systems, to prevent ice accretion on the blades, such as Fakken WF.

kken WF is an onshore WF, located on a small island called Vannøya to the north of Troms and Finnmark County, Norway. The WF is sited on a small hill at the southwestern edge of the island, at an altitude of 40 to $200 \mathrm{~m}$ above sea level Birkelund et al. (2018). A mountain range is located to the west of the WF and two large fjords to the south, forming a complex terrain surrounding the 
Table 2 Scoring criteria for wind farm performance

\begin{tabular}{|c|c|c|c|c|}
\hline & Score $(S)=1$ & $S=2$ & $S=3$ & $S=4$ \\
\hline \multicolumn{5}{|c|}{ Technical performance } \\
\hline $\begin{array}{l}\text { Capacity } \\
\text { Ozturk and } \\
\text { Fthenakis } \\
(2020)\end{array}$ & $\begin{array}{l}\text { Wind farm capacity factor } \\
\text { CF: } 10 \% \leq \mathrm{CF} \leq 20 \%\end{array}$ & $\begin{array}{l}\text { Wind farm capacity factor is } \\
20 \% \leq \mathrm{CF} \leq 30 \%\end{array}$ & $\begin{array}{l}\text { Wind farm capacity factor is } \\
30 \% \leq \mathrm{CF} \leq 40 \%\end{array}$ & $\begin{array}{l}\text { Wind farm capacity factor is } \\
\text { larger than } 40 \% \mathrm{CF} \geq 40 \%\end{array}$ \\
\hline Quality & $\begin{array}{l}\text { The manufacturing quality of } \\
\text { WTs and the quality of } \\
\text { used spare parts are not } \\
\text { satisfactory. The selected } \\
\text { WTs model is not } \\
\text { suitable for the WF site, } \\
\text { and the WF layout is not } \\
\text { well designed }\end{array}$ & $\begin{array}{l}\text { Good quality of WTs } \\
\text { manufacturing processes } \\
\text { and the used spare parts. } \\
\text { However, the selected WTs } \\
\text { model and the WF layout } \\
\text { could have been improved }\end{array}$ & $\begin{array}{l}\text { Good quality of WTs } \\
\text { manufacturing processes } \\
\text { and the used spare parts. } \\
\text { The selected WTs model } \\
\text { and the design layout of the } \\
\text { WF is good }\end{array}$ & $\begin{array}{l}\text { High quality of manufactured } \\
\text { WTs and the used spare } \\
\text { parts in maintenance } \\
\text { activities. The selected } \\
\text { WTs model is among the } \\
\text { most suitable for the WF } \\
\text { site, and the layout of the } \\
\text { WF is of high-quality } \\
\text { design }\end{array}$ \\
\hline \multicolumn{5}{|c|}{ Availability performance } \\
\hline $\begin{array}{l}\text { Reliability } \\
\text { Spinato et al. } \\
\text { (2009) }\end{array}$ & $\begin{array}{l}\text { The WTs experience a high } \\
\text { failure rate, more than } 3.5 \\
\text { failures per WT per year }\end{array}$ & $\begin{array}{l}\text { The average number of } \\
\text { failures per WT per year is } \\
\text { between } 2.5 \text { and } 3.5\end{array}$ & $\begin{array}{l}\text { The average number of } \\
\text { failures per WT per year is } \\
\text { between } 1.0 \text { and } 2.5\end{array}$ & $\begin{array}{l}\text { The average number of } \\
\text { failures per WT per year is } \\
\text { less than one }\end{array}$ \\
\hline $\begin{array}{l}\text { Maintainability } \\
\text { Ozturk and } \\
\text { Fthenakis } \\
\text { (2020) }\end{array}$ & $\begin{array}{l}\text { The time to repair a failure is } \\
\text { more than } 24 \mathrm{~h} \\
\text { TTR }>24 \mathrm{~h}\end{array}$ & $\begin{array}{l}\text { The time to repair a failure is } \\
\text { between } 16 \text { and } 24 \mathrm{~h} \\
16 \mathrm{~h}<\mathrm{TTR} \leq 24 \mathrm{~h}\end{array}$ & $\begin{array}{l}\text { The time to repair a failure is } \\
\text { between } 8 \text { and } 16 \mathrm{~h} \\
8 \mathrm{~h}<\mathrm{TTR} \leq 16 \mathrm{~h}\end{array}$ & $\begin{array}{l}\text { The time to repair a failure is } \\
\text { less than eight hours } \\
\text { TTR } \leq 8 \mathrm{~h}\end{array}$ \\
\hline $\begin{array}{l}\text { Supportability } \\
\text { Dao et al. } \\
(2019)\end{array}$ & $\begin{array}{l}\text { The mean downtime is more } \\
\text { than } 100 \mathrm{~h} \text { per failure }\end{array}$ & $\begin{array}{l}\text { The mean downtime is } \\
\text { between } 50-100 \mathrm{~h} \text { per } \\
\text { failure }\end{array}$ & $\begin{array}{l}\text { The mean downtime is } \\
\text { between } 25-50 \mathrm{~h} \text { per } \\
\text { failure }\end{array}$ & $\begin{array}{l}\text { The mean downtime is less } \\
\text { than } 25 \mathrm{~h} \text { per failure }\end{array}$ \\
\hline \multicolumn{5}{|c|}{ Sustainability performance } \\
\hline $\begin{array}{l}\text { Environmental } \\
\text { impact } \\
\text { Kucukali } \\
(2016)\end{array}$ & $\begin{array}{l}\text { The wind turbines are placed } \\
\text { on birds' migration route, } \\
\text { reindeers' grazing area or } \\
\text { near to an ecologically } \\
\text { sensitive area }\end{array}$ & $\begin{array}{l}\text { The wind farm has an } \\
\text { Environmental Impact } \\
\text { Assessment Report which } \\
\text { is prepared by a desk study. } \\
\text { But the wind farm is not } \\
\text { located in the vicinity of } \\
\text { wetlands, protected natural } \\
\text { areas, caves, and birds' } \\
\text { migration routes }\end{array}$ & $\begin{array}{l}\text { The wind farm has an } \\
\text { Environmental Impact } \\
\text { Assessment Report or study } \\
\text { which is supported with } \\
\text { field studies }\end{array}$ & $\begin{array}{l}\text { The wind farm has a detailed } \\
\text { Environmental Impact } \\
\text { Assessment Report in } \\
\text { which biodiversity issues } \\
\text { are addressed. The } \\
\text { environmental analysis is } \\
\text { supported with field } \\
\text { surveys, and a monitoring } \\
\text { system is established at the } \\
\text { site for relevant } \\
\text { environmental parameters }\end{array}$ \\
\hline $\begin{array}{l}\text { Economic } \\
\text { impact }\end{array}$ & $\begin{array}{l}\text { The price of electricity } \\
\text { generated by the wind farm } \\
\text { is } 26-50 \% \text { higher than what } \\
\text { households in the country } \\
\text { usually pay to purchase } \\
\text { electricity }\end{array}$ & $\begin{array}{l}\text { The price of electricity } \\
\text { generated by the wind farm } \\
\text { is } 1-25 \% \text { higher than what } \\
\text { households in the country } \\
\text { usually pay to purchase } \\
\text { electricity }\end{array}$ & $\begin{array}{l}\text { The price of electricity } \\
\text { generated by the wind farm } \\
\text { is equal to what households } \\
\text { in the country usually pay } \\
\text { to purchase electricity }\end{array}$ & $\begin{array}{l}\text { The price of electricity } \\
\text { generated by the wind farm } \\
\text { is cheaper than what } \\
\text { households in the country } \\
\text { usually pay to purchase } \\
\text { electricity }\end{array}$ \\
\hline $\begin{array}{l}\text { Social impact } \\
\text { Kucukali } \\
(2016)\end{array}$ & $\begin{array}{l}\text { The wind farm stops or limits } \\
\text { local communities' ability } \\
\text { to utilize the surrounding } \\
\text { lands and provide a } \\
\text { livelihood }\end{array}$ & $\begin{array}{l}\text { A public consultation process } \\
\text { has been not carried out, } \\
\text { but the wind farm does not } \\
\text { stop local communities' } \\
\text { ability to utilize the } \\
\text { surrounding lands and } \\
\text { provide a livelihood }\end{array}$ & $\begin{array}{l}\text { A public consultation process } \\
\text { has been carried out. The } \\
\text { locally affected community } \\
\text { has been notified and } \\
\text { adequate mitigation } \\
\text { measures have been taken }\end{array}$ & $\begin{array}{l}\text { A robust public consultation } \\
\text { process has been carried } \\
\text { out. No major objections } \\
\text { from local communities } \\
\text { were raised. The local } \\
\text { community may benefit } \\
\text { from the wind farm }\end{array}$ \\
\hline
\end{tabular}

WF. The WF consists of 18 Vestas V90-3.0 WTs with rated power 3.0 MW each, yielding a total installed capacity of $54 \mathrm{MW}$. The hub height of the turbines is $80 \mathrm{~m}$ above the ground, and the rotor diameter is $90 \mathrm{~m}$. The $18 \mathrm{WTs}$ are placed in two roughly parallel lines, as shown in Fig. 5, perpendicular to the southeastern inter-cardinal direction. It is assumed that the wind farm will operate for 25 years with no catastrophic operation and maintenance (O\&M) events. 


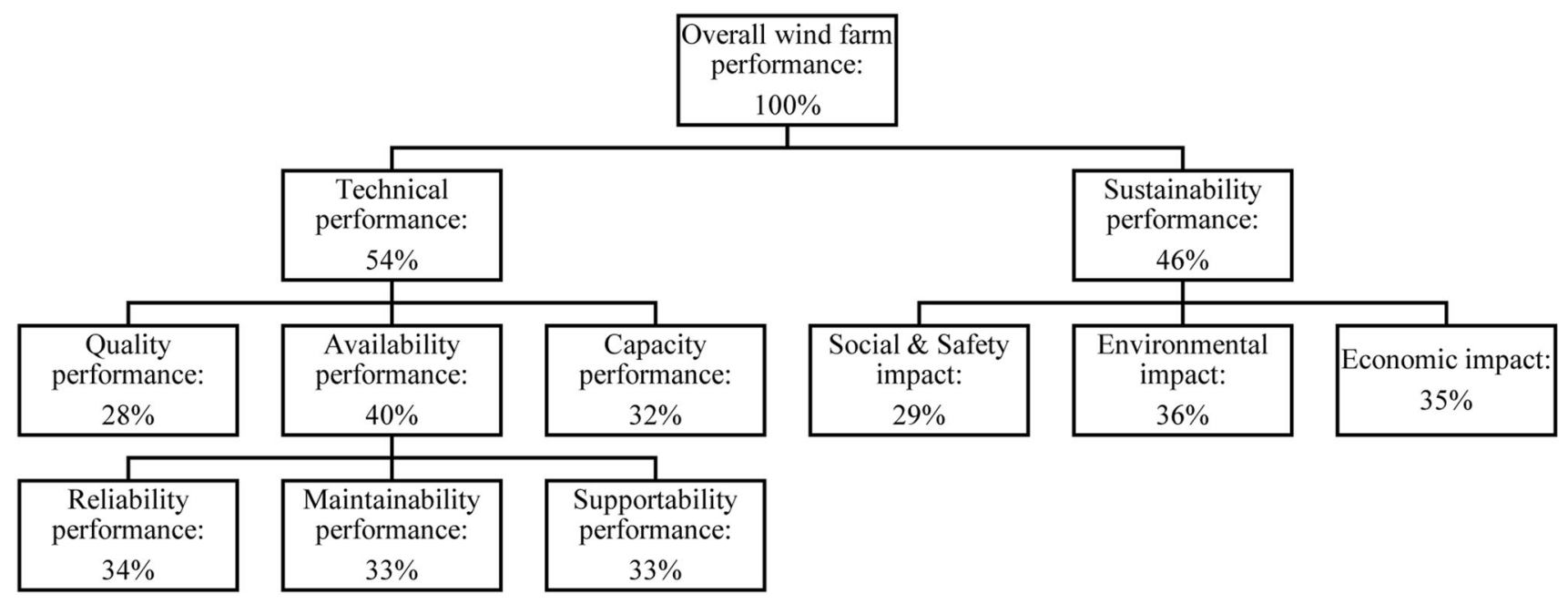

Fig. 3 Performance indicators relative weights, assessed by experts

Fig. 4 Relative weights of technical and sustainability performance indicators

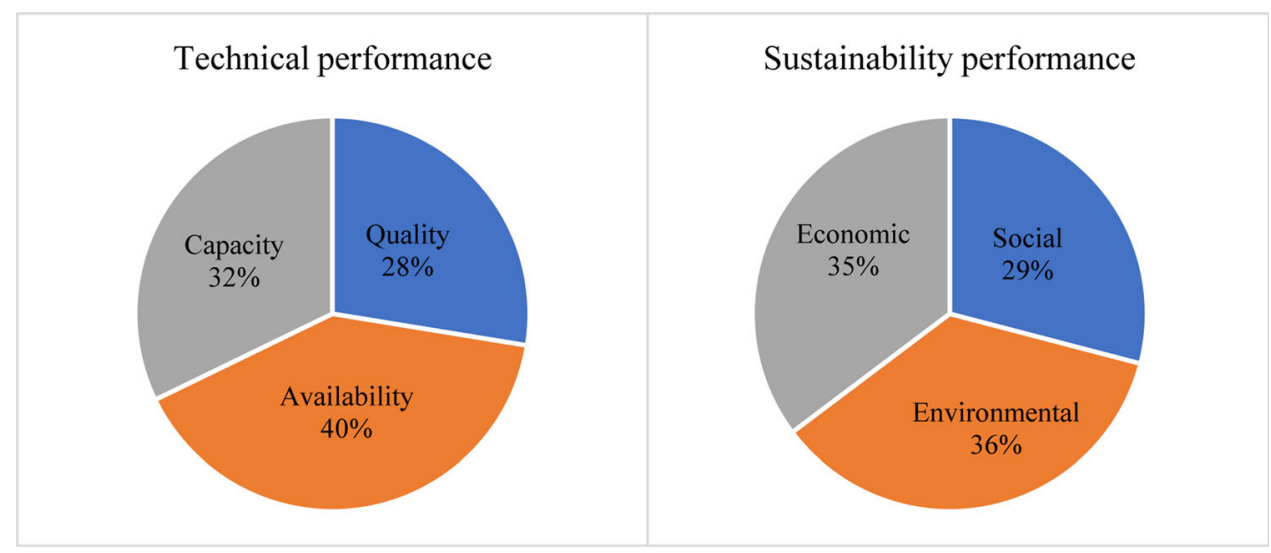

Fig. 5 Fakken wind farm layout

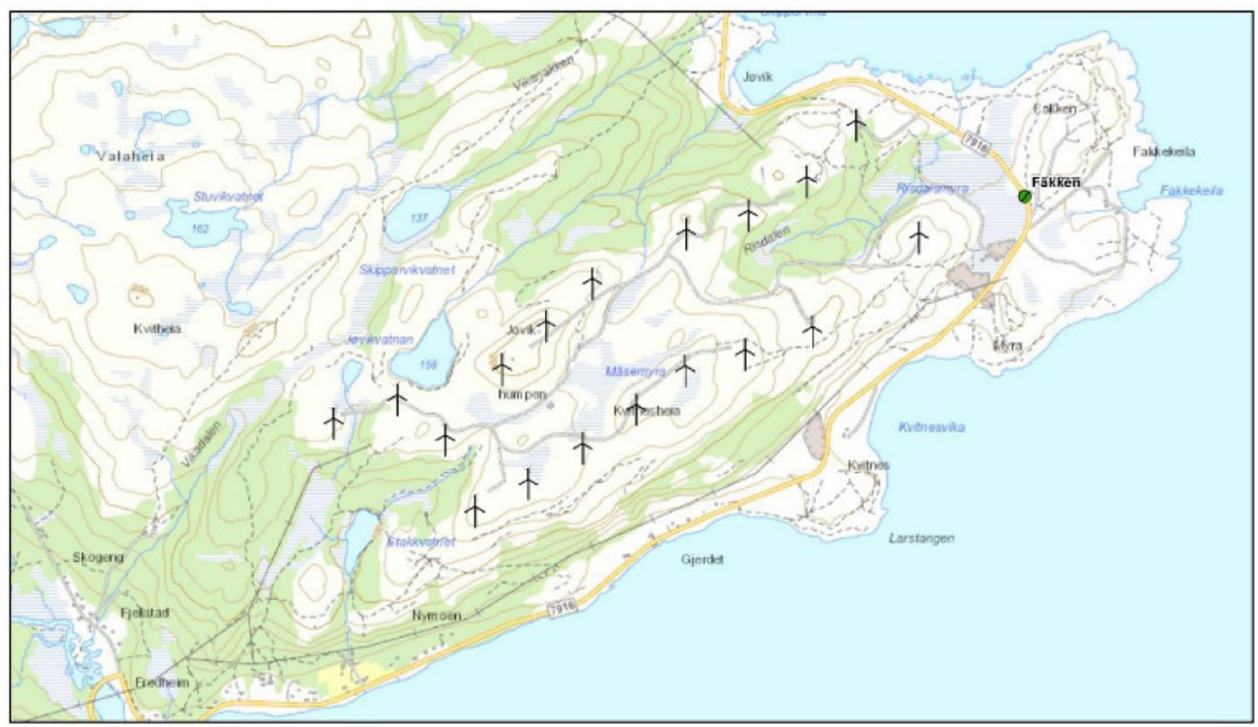




\subsection{Fakken WF performance indicators scores}

Through communication with the WF manager and operator, we were able to get our hands on 28 service reports, and more than two years of alarm logs that contained the operation and maintenance data of one wind turbine (WT No.8), for the period from January 2018 until July 2020. Based on the analysis of this data, the performance indicators criteria scores were selected from Table 2 and calculated using variations of Eq. (1), similar to Eq. (4), as can be seen in Fig. 6. The justification for the selection and calculation of the scores is shown in Sect. 3.1.1.

\subsubsection{Justification of scores}

Reliability. By reviewing the service reports for the reference WT (WT No. 8), it was found that the WT experienced three main failures during 2019 that led to its operation being halted: a hydraulic pump failure, a generator bearing failure, and a defective bearing on the generator's fan. Based on that, a score of 2 was assigned to the reliability performance of that WT. Moreover, an overall regular annual inspection of the WT took place twice during the period from January 2018 until July 2020. The regular inspections took place in August 2018 and 2019, with no major failures reported in either of the inspections.
Maintainability. According to the service reports, the mean time needed to replace the hydraulic pump, the generator's bearing and the generator's fan bearing were 10,21 and $2 \mathrm{~h}$, respectively. when referring to the scoring criteria Table 2, it is obvious that each time to repair of these failed components has a different criterion score as follows: the hydraulic pump has score of 3, the generator's bearing is assigned a score of 2 and the generator's fan bearing is assigned a score of 4 . Therefore, by taking the average of these scores, the maintainability of the WT can be assigned a value of 3 .

Supportability. Both failures, the hydraulic pump and the generator bearing failures, were repaired during the same day they failed, which means that the mean downtime for the WT per failure is less than $25 \mathrm{~h}$. Referring to Table 2, the supportability score is assigned a value of 4 .

Availability. The availability criteria score is a function of the reliability, maintainability and supportability performance indicators relative weights and criteria scores. By applying Eq. (4), the calculated availability criteria score is equal to 3 .

Quality. The quality of the manufactured WTs is high. Vestas, the WTs manufacturer, is a well-known and a pioneer company in the WTs manufacturing, selling, installing, and servicing. Fakken WF is being monitored remotely by Vestas, and in case of failure, Vestas takes

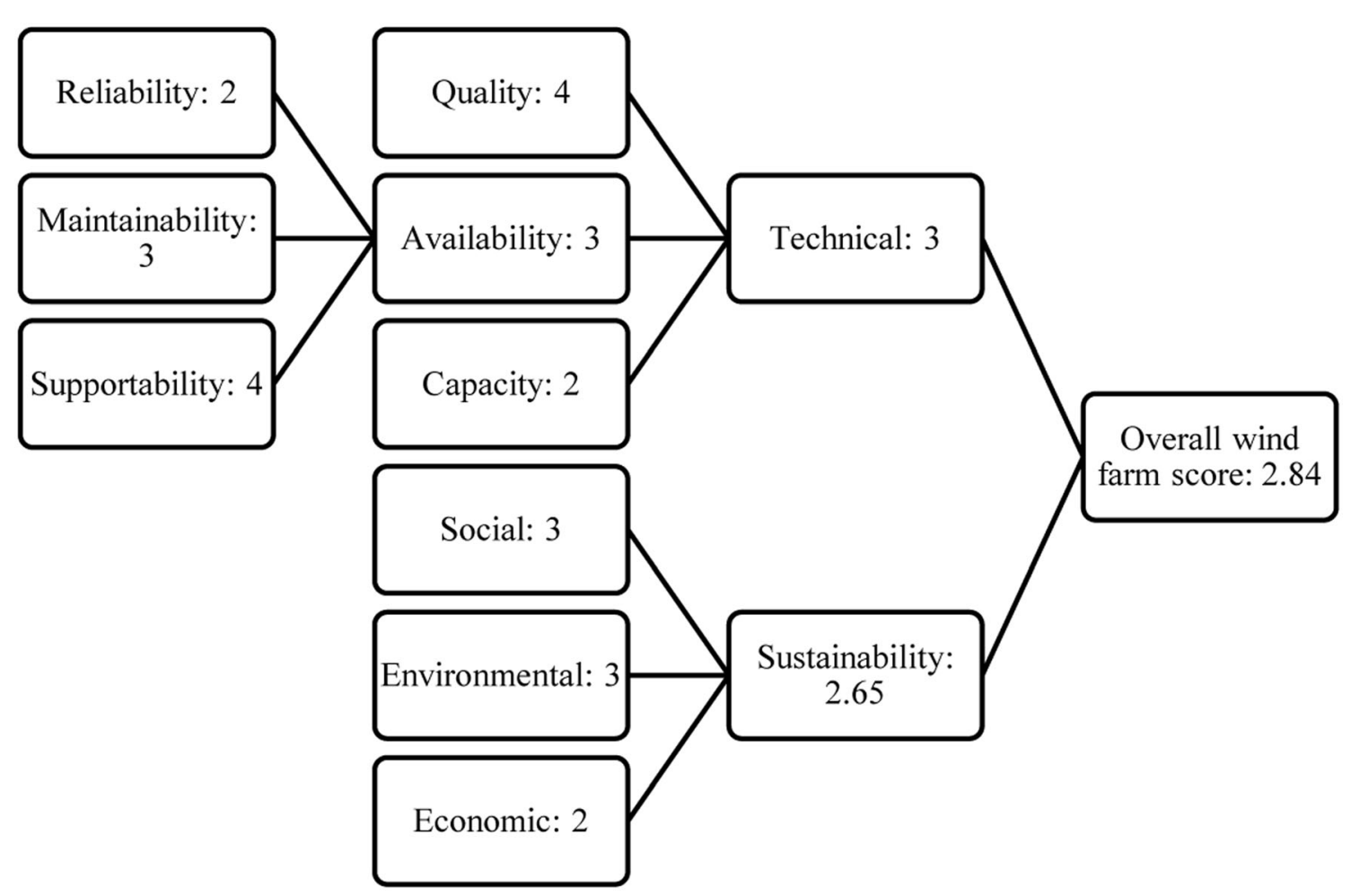

Fig. 6 Performance indicators scores for Fakken WF, based on Table 2 
care of the maintenance procedure required. Therefore, the quality of used spare parts is high. The selected model of WTs (V90-3 MW) is an improved design that provides more power without an appreciable increase in size, weight, and tower loads Vestas (2013). The design of the WF layout is based on research and measurements of wind speed, humidity, temperature, and other factors, which are still being monitored until today. Moreover, a highly efficient software was being used to analyze the measured data. Therefore, the quality performance is assigned a score of 4 .

Capacity. The amount of energy produced by the WF throughout the year is estimated at $130 \mathrm{GWh}$ TromsKraft (2018), divided by the maximum amount of energy the WF would have produced at full capacity, which is estimated at $473 \mathrm{GWh}$. The resulting capacity factor is $27.5 \%$. Based on that, the capacity performance is assigned a score value of 2.

Technical performance. The technical performance score can be calculated as a function of the availability, capacity and quality relative weights and criteria scores, by applying an equation similar to Eq. (4). The resulting value pf technical performance score is 3 .

Environmental impact. the WF is not located in bird migration routes and does not represent threats to endangered species in the Arctic. Still, the WF was built on an important winter grazing area for reindeer. However, testing data showed that reindeer density within the wind farm area did not change significantly during and after the construction of the wind farm, Tsegaye et al. (2017). The effects on reindeer spatial use during and after WF development were negligible, according to the same study. However, some significant changes in reindeers' use of the area was noticed that might be caused by human activities during certain construction stages of the WF. Based on that, the assigned environmental impact score of Fakken $\mathrm{WF}$ can be equal to 3 .

Economic impact. In the European Free Trade Association (EFTA) Surveillance Authority (ESA) report Sanderud and Monauni-Tömördy (2011), dated 16 March 2011, regarding the fund offered to Troms Kraft Produksjon AS to construct Fakken WF, Enova SF, a company owned by the Ministry of Climate and Environment in Norway, announced that the price of electricity from Fakken WF is calculated based on a six-month average of three year forward contracts, and it is going to be NOK $0.34 / \mathrm{kWh}$. Comparing this price of electricity to the average price paid by households in Norway during the same period, i.e. the three years following the construction of the wind farm, 2012, 2013 and 2014, as taken from Statistics Norway, SSB (2020), the price of electricity generated by Fakken WF was found to be $8 \%$ more expensive.
An estimation of the levelized cost of energy produced by Fakken WF was conducted by Mustafa et al. (2020). The cost estimation shows that the WF produces energy $25 \%$ more expensive than what households in Norway normally pay. However, households in Norway pay a unified price of electricity, whether it comes from wind energy or from hydropower, which is the main source of electricity in Norway. Therefore, the economic impact of Fakken WF has a score of 2.

Social impact. The WF is located in a remote site away from residential areas, so the noise generated by the WTs does not affect the local society. The WTs are not equipped with anti/de-icing systems, as ice rarely accretes on them. Therefore, the risk of ice throw from WTs is negligible. This was confirmed when speaking to the manager of the WF. Moreover, the WF does not stop or limit local communities' ability to utilize the surrounding lands and gain a livelihood. However, some claims surfaced from the local community regarding the effects of the WTs on reindeers' use of the WF area, but these claims were disproved, by Tsegaye et al. (2017). Based on that, the social impact score is assigned a value of 3 .

Sustainability performance. The sustainability performance score can be calculated as a function of the environmental, economic, and social impacts' relative weights and criteria scores, by applying an equation similar to Eq. 4. The resulting sustainability performance score is 2.65 .

Overall WF performance score. The overall performance score is a function of the technical and sustainability performances' relative weights and scores. By using Eq. (5), the resulting value of the overall performance score of Fakken WF is equal to 2.84 .

\subsection{Fakken WF overall performance index}

The proposed OPI is a normalized value of the overall WF performance score, which was calculated using Eq. 3. The value of the overall performance score is normalized to be from 0 to 1 . This can be done by subtracting the lowest attainable score, which is 1 from the calculated overall performance score and dividing the result by the difference between the highest (4) and lowest (1) attainable scores, as shown in Eq. 6:

$$
\begin{aligned}
\text { OPI } & =\frac{\text { overall performance score }- \text { minimum score }}{\text { maximum score }- \text { minimum score }} \\
& =\frac{2.84-1}{3}=0.613
\end{aligned}
$$

The resulting OPI represents an absolute value that can help operators and stakeholder at a specific WF to decide whether the overall performance of that WF is acceptable or not. In case the resulting OPI was deemed to be 
Table 3 A qualitative scale for expressing the OPI

\begin{tabular}{ll}
\hline OPI & Scale \\
\hline $0-25 \%$ & Bad performance \\
$26-50 \%$ & Average performance \\
$51-75 \%$ & Good performance \\
$76-100 \%$ & Excellent performance \\
\hline
\end{tabular}

unacceptable, the performance indicator that contributes to lowering the overall WF performance can be easily allocated. Moreover, the resulting OPI can be expressed qualitatively by defining a qualitative scale as show in Table 3.

Based on that, the $61.3 \%$ OPI can be expressed to be good performance. In case the decision was to improve the OPI of Fakken WF, it can be seen, by referring to Fig. 5, that the sustainability performance indicates a lower impact than the technical performance. Therefore, improvements should be focused on the WF sustainability performance. Moreover, it is the economic performance indicator that has the lowest score among sustainability performance indicators. This can be attributed to the high operation and maintenance $(\mathrm{O} \& \mathrm{M})$ costs that lead to increasing the cost of energy produced by the WF. Based on that, it can be proposed that more efforts are required to improve the (O\&M) activities.

Another advantage of using the OPI is that it can be calculated for multiple WFs that share similar characteristics, such as WTs brands, capacity, location, etc. The OPI can help us compare the overall performance of these WFs, or their specific performance indicators, and therefore, ranke them according to how high or how low their performances are. For example, the OPI of Fakken WF can be compared with other WFs located in Arctic Norway, such as Nygårdsfjellet and Kvittfjell/ Raudfjell WFs. Based on the resulting OPI values, decision-makers can decide which WFs need to be improved to provide better performance and which performance indicators need more focus.

In order to compare the effects of Arctic operating conditions on the calculated OPI of Fakken WF, the same OPI quantification methodology is applied to a WF located in a non-cold-climate region, in Turkey. The Kozbeyli WF in Turkey has higher technical performance than Fakken WF, with a technical performance criterion score equal to 3.73 out of 4 , due to higher reliability and capacity performances. This has led to an OPI value of nearly $75 \%$ if the sustainability performance of Kozbeyli WF was equal to that of Fakken WF, which is not the case. This is due to a lower environmental performance as Kozbeyli WF is located close to an Environmental Protected Area, migration route of birds, and endangered species. In addition, the Kozbeyli WF is $1.3 \mathrm{~km}$ away from a village that has a touristic value, which has reduced the social acceptance and performance of the WF Kucukali (2016) that consequently, reduces the sustainability performance criteria score of the WF to 1.7 out of 4 . Consequently, the resulting OPI of Kozbeyli WF is nearly $60 \%$, which is mainly due to lower sustainability performance of the WF.

\section{Conclusions}

The OPI is an important tool in providing a measure of the overall performance of WFs, especially in cases where performance data is scarce. The overall performance of WFs constituted the technical and sustainability performance indicators. The technical performance consisted of the quality, capacity, and availability performance indicators. The weighted sum method (WSM) is one of the most widely used methods for multiple-criteria decision making (MCDM). The use of WSM implies summing the products of the performance indicators relative weights and their scores of criteria.

Due to data scarcity, the relative weight of each performance indicator was estimated using expert judgement technique. Experts estimated that the technical performance had higher relative weight $(54 \%)$ than the sustainability performance $(46 \%)$. The rest of performance indicators had relative weights estimated by the experts as follows: Quality (28\%), Capacity (32\%), Availability (40\%), Reliability (34\%), Maintainability (33\%), and Supportability $(33 \%)$. Moreover, the sustainability performance indicators had the following relative weights: social and safety impacts (29\%), environmental impacts (36\%), and the economic impacts (35\%).

The proposed methodology was applied to an onshore WF in Arctic Norway, called Fakken WF. The assigned and calculated scoring criteria for the performance indicators using Table 2 are found to be as follows: Reliability (2), Maintainability (3), Supportability (4), Availability (3), Quality (4), Capacity (2). The calculated technical performance score is equal to 3 . The sustainability performance indicators had the following criteria scores: social and safety impacts (3), environmental impacts (3), and the economic impacts (2). The calculated sustainability criteria score is equal to 2.65 . Consequently, the calculated total criteria score for the WF was found to be equal to 2.84 .

The calculated OPI of the WF is $61.3 \%$, which was deemed to be good, when compared against a proposed qualitative criteria scale. The OPI indicated that the economic performance of the WF needs to be improved, which can be attained by lowering the O\&M costs to lower the cost of energy of the WF. Moreover, in order to understand 
the effects of Arctic operating conditions on the performance of WFs, the OPI of Fakken WF has been compared to the OPI of Kozbeyli WF, which is a WF located in a non-cold-climate region. The comparison concluded that Kozbeyli WF had higher technical performance in its reliability and capacity performances, due to the absence of Arctic operating conditions. However, the location of Kozbeyli WF has led to lowering its sustainability performance, due to its negative impacts on the environment and society, which has led a lower OPI value (60\%), which was lower than the OPI of Fakken WF.

Funding Open access funding provided by UiT The Arctic University of Norway (incl University Hospital of North Norway). This research is funded by UiT the Arctic University of Norway.

Availability of data and material Data and used material in the paper are available upon request.

\section{Declarations}

Conflict of interest The authors declare that they have no conflict of interest.

Open Access This article is licensed under a Creative Commons Attribution 4.0 International License, which permits use, sharing, adaptation, distribution and reproduction in any medium or format, as long as you give appropriate credit to the original author(s) and the source, provide a link to the Creative Commons licence, and indicate if changes were made. The images or other third party material in this article are included in the article's Creative Commons licence, unless indicated otherwise in a credit line to the material. If material is not included in the article's Creative Commons licence and your intended use is not permitted by statutory regulation or exceeds the permitted use, you will need to obtain permission directly from the copyright holder. To view a copy of this licence, visit http://creativecommons. org/licenses/by/4.0/.

\section{References}

Alsabagh ASY, Tiu W, Xu Y, Virk MS (2013) A review of the effects of ice accretion on the structural behavior of wind turbines. Wind Eng 37(1):59-70

Barabady J, Markeset T, Kumar U (2010) Review and discussion of production assurance program. Int $J$ Qual Reliab Manage 27(6):702-720

Battisti L (2015) Wind turbines in cold climates, icing impacts and mitigation systems. Springer International Publishing, Switzerland

Beaudrie CE, Kandlikar M, Ramachandran G (2016) Using Expert Judgment for Risk Assessment. Assessing Nanoparticle Risks to Human Health. William Andrew Publishing, New York, pp 91-119

Birkelund Y, Alessandrini S, Byrkjedal Ø, Monache LD (2018) Wind power predictions in complex terrain using analog ensembles. In: Paper presented at the Wind Europe conference 2018 within the Global Wind Summit, Hamburg, Germany, 25-28 Sptember 2018
Böğürcü M (2012) Investigation of sectoral priorities for cleaner (sustainable) production at regional and national level

Bredesen RE, Refsum H (2015) Methods for evaluating risk caused by ice throw and ice fall from wind turbines and other tall structures. In IWAIS conference 2015

Colson AR, Cooke RM (2018) Expert elicitation: using the classical model to validate experts' judgments. Rev Environ Econ Policy 12(1):113-132

Dai H, Zhang K, Xu X, Yu H (2012) Evaluation on the effects of deicing chemicals on soil and water environment. Procedia Environ Sci 13:2122-2130

Dao C, Kazemtabrizi B, Crabtree C (2019) Wind turbine reliability data review and impacts on levelised cost of energy. Wind Energy 22(12):1848-1871

Diaz-Balteiro L, González-Pachón J, Romero C (2017) Measuring systems sustainability with multi-criteria methods: a critical review. Eur J Oper Res 258(2):607-616

Fortin G, Perron J, Ilinca A (2005) Behaviour and modeling of cup anemometers under Icing conditions. In: Proceedings of the International workshop on atmospheric icing of structures (IWAIS XI), Montréal, June 2005

IEC (2015) Dependability. Basic concepts: International Electrotechnical Commission

JICA (2011) The study on optimal power generation for peak demand in turkey. Japan International Cooperation Agency

Kilpatrick R, Hildebrandt S, Swytink-Binnema N, Clément M (2020) Advances in wind power forecasting and power loss mitigation for cold climate operation. Paper presented at the NAWEA WindTech 2019, Amherst, MA USA, 14-16 October 2019

Koo C, Hong T, Oh J, Choi J-K (2018) Improving the prediction performance of the finite element model for estimating the technical performance of the distributed generation of solar power system in a building façade. Appl Energy 215:41-53

Kucukali S (2016) Risk scorecard concept in wind energy projects: An integrated approach. Renew Sustain Energy Rev 56:975-987

Laakso T, Peltola E (2005) Review on blade heating technology and future prospects. In: BOREAS VII: Impact of icing on wind energy production and other fields of activities, 2005: Ilmatieteen laitos

Lawrence R, Moritz S (2019) Mining industry perspectives on indigenous rights: corporate complacency and political uncertainty. Extract Ind Soc 6(1):41-49

Lu J, Bui MT, Yuan F (2019) Evaluation of the water quality at Bogdalen watershed near Kvitfjell and Raudfjell wind farm area. In: IOP Conference Series: Earth and Environmental Science, Vol 344, pp 012022, vol 1, IOP Publishing, Bristol

Mermet S, Gehant B (2011) Risk management for hydroelectric power plants. In Proceedings of hydro 2011 conference

Musango JK, Brent AC (2011) A conceptual framework for energy technology sustainability assessment. Energy Sustain Dev 15(1):84-91

Mustafa AM, Barabadi A, Markeset T (2019) Risk assessment of wind farm development in ice proven area. In: Proceedings of the 25 th international conference on port and ocean engineering under arctic conditions (POAC), Delft, The Netherlands, June 9-13, 2019

Mustafa AM, Markeset T, Barabadi A (2020) Downtime cost estimation: a wind farm in the arctic case study. Paper presented at the Esrel 2020, Italy

Naseri M, Barabady J (2016) On RAM performance of production facilities operating under the Barents Sea harsh environmental conditions. Int J Syst Assur Eng Manage 7(3):273-298

Naseri M, Fuqing Y, Barabady J (2015) Performance-based aggregation of expert opinions for reliability prediction of Arctic offshore facilities. In: 2015 IEEE International Conference on 
Industrial Engineering and Engineering Management (IEEM) pp 1062-1066, IEEE

Ozturk S, Fthenakis V (2020) Predicting frequency, time-to-repair and costs of wind turbine failures. Energies 13(5):1149

Parent O, Ilinca A (2011) Anti-icing and de-icing techniques for wind turbines: critical review. Cold Reg Sci Technol 65(1):88-96

Rastayesh S, Long L, Dalsgaard Sørensen J, Thöns S (2019) Risk assessment and value of action analysis for icing conditions of wind turbines close to highways. Energies 12(14):2653

Sanderud P, Monauni-Tömördy S (2011) EFTA surveillance authority decision on on the aid to Troms Kraft Produksjon AS for Fakken Wind Park. Brussels

Sovacool BK (2009) Contextualizing avian mortality: A preliminary appraisal of bird and bat fatalities from wind, fossil-fuel, and nuclear electricity. Energy Policy 37(6):2241-2248

Spinato F, Tavner PJ, Van Bussel GJ, Koutoulakos E (2009) Reliability of wind turbine subassemblies. IET Renew Power Gener 3(4):387-401

SSB (2020) Electricity price, grid rent and taxes for households 2012 - 2019. https://www.ssb.no/en/statbank/table/09007/. Accessed 23rd September 2020

Stanujkic D, Zavadskas EK (2015) A modified weighted sum method based on the decision-maker's preferred levels of performances. Stud Inf Control 24(4):461-470
Triantaphyllou E (2000) Multi-criteria decision making methods. In Multi-criteria decision making methods: A comparative study. Springer, Berlin, pp 5-21

TromsKraft (2018) Fakken vindpark. https://www.tromskraft.no/omkonsernet/vare-selskap/troms-kraft-produksjon/fakken-vindpark/ . Accessed 31st March 2020

Tsegaye D, Colman JE, Eftest $\varnothing 1$ S, Flydal K, Røthe G, Rapp K (2017) Reindeer spatial use before, during and after construction of a wind farm. Appl Anim Behav Sci 195:103-111

Vestas WSAS (2013) Vestas V90-3.0 MW

Wei K, Yang Y, Zuo H, Zhong D (2020) A review on ice detection technology and ice elimination technology for wind turbine. Wind Energy 23(3):433-457

Welch JB, Venkateswaran A (2009) The dual sustainability of wind energy. Renew Sustain Energy Rev 13(5):1121-1126

Williamson S, Stark B, Booker J (2014) Low head pico hydro turbine selection using a multi-criteria analysis. Renew Energy 61:43-50

Zaki R (2020) Performance measurement system in complex environment: observed and unobserved risk factors

Publisher's Note Springer Nature remains neutral with regard to jurisdictional claims in published maps and institutional affiliations. 